\title{
Lessons learned: what the COVID-19 global pandemic has taught us about teaching, technology, and students with autism spectrum disorder
}

\author{
Jane Roitsch, Robert L. Moore and Annemarie L. Horn
}

Jane Roitsch is based at the Department of Communication Disorders and Special Education, Old Dominion University, Norfolk, Virginia, USA. Robert L. Moore is based at the School of Teaching and Learning, University of Florida, Gainesville, Florida, USA. Annemarie L. Horn is based at the Department of Communication Disorders and Special Education, Old Dominion University, Norfolk, Virginia, USA.
Received 3 December 2020 Revised 19 February 2021 28 February 2021

Accepted 3 March 2021

\begin{abstract}
Purpose - The purpose of this paper is to examine the impact of the abrupt transition from attending school face-to-face to participating in online learning in response to the COVID-19 pandemic as reported by a parent of a student with autism spectrum disorder (ASD).

Design/methodology/approach - A phone interview was conducted with the parent of a child with $A S D$. The semi-structured interview focused on how the child's family was impacted when classes shifted to virtual from face-to-face learning in response to the COVID-19 pandemic.

Findings - A total of four themes emerged from the interview. Three of these included adjustments to changes in routines and roles, instruction, and social interactions. A final theme involved the benefits and challenges that emerged following the transition to online learning for students with ASD. While we are in an unprecedented time with the COVID-19 global pandemic presenting understandable challenges, opportunities for and examples of effective virtual learning environments for students with ASD were reported in the parent interview and supported by the literature.
\end{abstract}

Practical implications - This research provides insight regarding the impact of COVID-19 and highlights elements that should be considered involving technology for students with ASD. Increased awareness regarding the benefits and contraindications of technology while teaching students with ASD can minimize the adverse effects and enhance the positive impact of technology in students with $A S D$.

Originality/value - This paper shares the experiences of one parent of a child with ASD and their experiences with technology and learning during COVID-19.

Keywords Technology, autism spectrum disorder, pandemic, COVID-19, learning environments, online education of students with disabilities

Paper type Research paper

Introduction

\section{Autism spectrum disorder}

According to the Diagnostic and Statistical Manual of Mental Disorders Fifth Edition (DSM-5), an individual with a diagnosis of autism is referred to as having 'autism spectrum disorder (ASD).' For that reason, in this paper, we refer to this population of individuals as those with ASD. Also according to the American Psychiatric Association's Diagnostic and Statistical Manual, fifth edition (DSM-5), an individual diagnosed with ASD has persistent deficits in the following areas of social communication and interaction: social-emotional interchange, nonverbal communicative behaviors used during social interactions and developing, maintaining and understanding relationships; and impairments in restricted repetitive patterns of behavior in at least two of the following areas: repetitive behavior as observed through motor 
movements, use of objects or speech, inflexibility with routines, insistence on sameness, or ritualized patterns, restricted and fixated interests with atypical levels of intensity and focus and hyper- or hyporeactivity to sensory input (American Psychiatric Association, 2013). Approximately one in 54 children in the USA and one in 160 children worldwide has ASD (Maenner et al., 2020).

The Centers for Disease Control and Prevention (CDC, 2020) reports that persons with ASD might demonstrate the following characteristics: not point at objects to show interest, not look at objects when another person points at them, have trouble relating to others or not have an interest in other people at all, avoid eye contact and want to be alone, have trouble understanding other people's feelings or talking about their own feelings, prefer not to be held or cuddled, or might cuddle only when they want to, appear to be unaware when people talk to them, but respond to other sounds, be very interested in people, but not know how to talk, play or relate to them, repeat or echo words or phrases said to them, or repeat words or phrases in place of normal language, have trouble expressing their needs using typical words or motions, not play "pretend" games (for example, not pretend to "feed" a doll), repeat actions over and over again, have trouble adapting to changes in routine, have unusual reactions to the way things smell, taste, look, feel or sound and/or lose skills they once had (for example, stop saying words they were using).

Must et al. (2015) found students with ASD were more likely to use computers and televisions than spend time outside or with their friends compared to their typically developing peers. Persons with ASD also have been shown to use the internet frequently (Mazurek et al., 2012) and may demonstrate increased internet-related problems such as poor social skills in social interactions and difficulty in determining appropriate internet behaviors (Romano et al., 2013).

\section{Academic strengths and challenges in students with autism spectrum disorder}

In school, the challenges that students with ASD demonstrate may include narrow learning, language development issues, poor non-verbal skills, narrow interests, and attention difficulties (Applied Behavior Analysis Program Guide, 2020). Many students with ASD require support to achieve academic success (Able et al., 2015). Focusing on individual strengths and interests in students with ASD can improve learning outcomes (Kluth and Schwarz, 2008). Technology has helped increase independence in students with ASD while simultaneously decreasing reliance on staff support benefits (Horn et al., 2021). The use of technology in education has been shown to help people with ASD develop skills and even enrich learning environments in ways face-to-face classrooms may not (Valencia et al., 2019).

\section{Technology and autism spectrum disorder}

In a systematic review of the literature, Valencia et al. (2019) examined how technology impacts learning in students with ASD. Their findings revealed engaging in simulated learning environments offered through virtual platforms (e.g. virtual reality, mixed reality and augmented reality) led to favorable outcomes and sustained learning for people with ASD. In sum, the use of simulated conversations and avatars for students with ASD has provided a means of education, training and therapy that focuses on pragmatic and social skills in a realm unknown and unavailable just 20 years ago.

It has been shown that students with ASD who engage in simulated learning experiences (i.e. video modeling and computer-based simulation training) can generalize acquired skills into natural environments (Ayres et al., 2009). For example, when students use simulation for the purpose of improving social interactions with peers, the experience enables them to get immersed in a "safe" environment where they can receive feedback on their behavior and repeatedly practice skills (Parsons and Mitchell, 2002; Yuan and Ip, 2018). As the 
target skill (s) improve, those skills have been shown to improve in face-to-face interactions as well (Kandalaft et al., 2013).

\section{COVID-19}

The COVID-19 pandemic seemingly overnight caused a global shift in everyday life as businesses, schools and entire countries were forced to move completely online (Adedoyin and Soykan, 2020; Brenan, 2020; Schuck and Lambert, 2020; UNESCO, 2020). Although adjustments were required in response to the global health emergency, the suddenness of the change has brought attention to online education, specifically around access to technology and learning environments (Adedoyin and Soykan, 2020; Hodges et al., 2020; Masonbrink and Hurley, 2020; Schuck and Lambert, 2020). The shift to online education following the COVID-19 pandemic has also presented opportunities to revisit how instruction is designed, delivered and supported (Hodges et al., 2020; Moore, 2020).

Distance education became the norm for students around the world when the COVID-19 global pandemic began in the spring of 2020 (Brenan, 2020; Hodges et al., 2020) as schools around the globe shifted from school-based face-to-face learning to various virtual, learn-from-home models (UNESCO, 2020). A spotlight was shone on parent and teacher relationships during the COVID-19 global pandemic as many previously delegated instructional responsibilities shifted to parents (Noguchi, 2020; Reynolds, 2020; Schuck and Lambert, 2020). Students were required to adjust schedules, adapt to remote learning formats in the home environment and complete schoolwork on a computer or tablet. This remote learning, best described as emergency remote teaching (ERT) (Hodges et al., 2020), was jarring for everyone. It also was particularly sudden for parents as they now were assuming new roles as instructors - and many were simply not prepared for this (Noguchi, 2020; Reynolds, 2020; Schuck and Lambert, 2020).

In response to the change to virtual learning, parents of children with disabilities not only need to keep up with instruction but they are also tasked with supporting their child's special education and related service needs. For students who have more complex disabilities (e.g. ASD), meeting their individualized education, social, and emotional needs in a virtual learning environment is not an easy feat. Therefore, one area that requires more research involves online instruction with students with disabilities. In this paper, we explore how the COVID-19 global pandemic reshaped special education services with a particular focus on instruction delivered to students with ASD. We endeavored to examine the perspective of one parent of a child with ASD to investigate perceptions of the impact of transitioning to online learning for her son. We were guided by the following questions:

$R Q 1$. What perspectives does one parent have on the impact of the transition from faceto-face to online learning had for her son with ASD?

$R Q 2$. What does current literature report involving the impact of the transition from faceto-face to online learning for students with ASD?

RQ3. What, if any, themes emerge from the results of the aforementioned parent report and current literature?

\section{Methods}

The first author had the opportunity to interview the mother of a 13-year-old son with ASD regarding how the COVID-19 global pandemic and shift to online learning had impacted her son. At the time of the interview, the child was in a seventh-grade inclusion classroom in a public school. Due to COVID-19, he was required to transition to a virtual learning environment. The author had a prior working relationship with the parent and had already established rapport with the parent. The interview was more of a free-flowing conversation that gave space for the parent to share her experiences during COVID-19. The focus of the 
conversation was on understanding how the family was impacted when classes shifted to virtual from face-to-face learning in response to the COVID-19 pandemic. As the conversation progressed, the first author asked follow-up or probing questions to have the mother elaborate on topics such as educational changes or other observable changes with her child.

\section{Procedure and instrumentation}

The first author used a semi-structured interview method to hear from the mother, "Elizabeth," about her perceptions of the impact of the transition from face-to-face to online learning. The interview began with an open-ended question: How was her family impacted when classes shifted to virtual from face-to-face learning in response to the COVID-19 pandemic? Elizabeth was asked to elaborate and speak freely to about the educational and other observations about her child and her family that resulted from the sudden change in educational placement and service delivery. The first author and a trained graduate assistant (GA) listened to the recorded interview and the summarized responses. The GA transcribed the interview and the two raters then independently identified themes for reliability. They then worked together to reach agreement on the themes that emerged from the interview. Ultimately four themes emerged: changes in roles and routines; changes in instruction; changes in social interaction; and benefits and challenges to online instruction.

\section{Results}

A total of four themes emerged from the interview with Elizabeth and these reflect the impact of the change from face-to-face to online instruction for her child with ASD. Specifically, these themes included adjustments to changes in: routines and roles, instruction, social interactions for students with ASD and the benefits and challenges following the transition to online learning for students with ASD.

\section{Changes in roles and routines}

The new responsibility of becoming educators was challenging for all parents, but particularly for parents of students with ASD for several reasons. Elizabeth shared:

Everything stopped. Then it started up faster than ever. That's what I tell people when they ask how the pandemic affected us. We thought he would be back in school. Then when he wasn't, we felt like we had to work so hard, so fast, to put supports in place, get coverage at home, learn the computer programs he needed for school, all the while still working my job and making sure our daughter attended her school virtually. It was slow then so fast [... . we are still trying to catch up.

In addition, parents often had to contend with their student with ASD's inability to adjust to a disruption in routine - a characteristic often identified as one of the cardinal behavioral challenges in persons with ASD (CDC, 2020). For some, the change in routines for students with ASD during the COVID-19 pandemic has been palpable. Elizabeth shared a short story about her son:

His world changed more than ours did with the pandemic. We had worked for years to establish a plan and stick to it every morning, and that included making his bed, getting breakfast, and waiting for the bus. In fact, he learned to tell time because of the bus. He knew that at 7:20 every weekday morning, the bus picked him up, and the bus brought him home every day at 3:45. No longer did time have any meaning so we noticed within a month, he wasn't able to tell time anymore. He also didn't understand why he couldn't go to school because he wasn't sick. It was a really rough few months. 


\section{Changes in instruction}

The next challenge was from the instructional approach. At the onset of the sudden shift to virtual instruction, most schools did not have an online contingency plan in place, which caused delays in direct access to live remote instruction (i.e. teacher-delivered synchronous instruction) (UNESCO, 2020). Rather, some schools opted to provide handouts and paper materials, while others attempted online instruction via asynchronous instruction and/or shared learning websites with students. The quality and amount of both has been shown to be dependent on the school district, type of school system (e.g. private or public), access to technology, parental involvement and student engagement.

For students with ASD, instruction has typically focused on high levels of student support provided by teachers, things not easily replicated in virtual settings (Stenhoff et al., 2020). Elizabeth explained that: [Prior to the pandemic] My son was using Bluetooth headphones in class to help minimize his distractions. His teachers were also able to provide his assignments in larger font on his Chromebook and make the use of the computer very simple for him. He seemed to really enjoy using the computer. He was able to complete more assignments that way than on paper. Following the shift to virtual learning, instead of the individualized support provided by qualified special education teachers, responsibilities moved to parents - many of whom were not prepared and lacked training (Schuck and Lambert, 2020). Designing high quality and engaging online courses requires a significant amount of time (Moore, 2016; Oyarzun et al., 2020) and due to the unexpected school closures resulting from COVID-19, teachers were not given adequate time to prepare their online learning environments (Hodges et al., 2020; Tate, 2020). High-contact and in-depth instructional approaches that worked well in face-to-face settings did not translate well in virtual settings (Schuck and Lambert, 2020). The transition to virtual learning brought to light the challenges faced by many students with disabilities who did not have in-person access to support staff. Virtual learning requires students to operate a computer independently or with minimal supports while staying actively engaged in the lesson. Schuck and Lambert (2020) found the support and individualized instructional needs of students with disabilities to not be met in the virtual learning environment.

\section{Changes in social interactions}

Other considerations included the social limitations of online learning. Knowing that interpersonal exchanges are significantly reduced with online instruction versus face-toface learning, increasing technology use may feel like a double-edged sword for parents and teachers working to increase communication and social skills of students with ASD. This was highlighted by Elizabeth: My son definitely prefers his technology devices to talking with anyone. If I did not manage the amount of time he can use them, he would be on them from sun-up to sun-down. I think he feels safe, not threatened, and in control when he's on his tablet or computer. It is his world and he can do what he wants. That's very much his mind, and the mind of most persons with autism. It is my job as a parent to get him out in the world, and not let him always stay in his own one [... . the one he creates.

\section{Benefits and challenges of the transition to online learning}

Benefits. Researchers in Australia investigated how students with ASD and their parents were dealing with the COVID-19 global pandemic and the transition to online education (Pellicano et al., 2020). A total of 35 adults with ASD and 80 parents of children with ASD (including 35 parents with ASD of children with ASD) were interviewed, as well as 16 school-aged students with ASD between 12 and 18 years of age. The researchers identified benefits and challenges related to the COVID-19 global pandemic for parents of school-aged students with ASD. Positive experiences included strengthened family relationships, flexibility in time and space, a feeling of social solidarity with others, and 
service provision success (Pellicano et al., 2020). Elizabeth shared similar sentiments: What surprised us the most was how much more capable he was with the online assignments. I should have figured he would be good at computer-related work because he plays a lot of games online, but I was still surprised how he was able to open folders, download assignments and also remember what to do from one day to the next to navigate to different learning platforms. One day he had a test to take, which required him opening up a new website, entering a username and password given by the teacher, and complete the test. He did so without any help, and I was amazed. One of the best things to come out of all this is not only my son's increased ability to communicate and complete his work (his typing has improved a lot, too!). Another significant "plus" has been my learning. If I had not been required to learn the platforms and implement the learning materials required for my son, I would not know his strengths or his weaknesses as I do now. It (the COVID-19 pandemic and learning from home) really has helped me appreciate his teachers and improved our lines of communication. There have been some roses that have arisen out of these thorns after all.

Challenges. In the Pellicano et al. (2020) study that queried students, adults and parents of children with ASD during the COVID-19 global pandemic, participants reported increased anxiety related to social, health and emotional challenges related to the pandemic, loss of the everyday, challenges with tele-education and telehealth, lack of message clarity regarding how to manage and protect themselves from COVID-19, and missing friends and social connections. Elizabeth noticed a similar situation with her son: Whenever I ask him about school and if he sat with anyone at lunch, or played with anyone at recess, he would always reply, "No." I was shocked when he said, "I miss Mr. Davey," about a month after they had been transitioned to online learning. Mr. Davey is the school's custodian who has always been at the school where my son has attended. I never made the connection that even though there may have been no other student my son connected with, he had an adult at school who probably was kind to him, spoke to him, or somehow piqued his interest. And to that end, he missed seeing him as he did every day once the face-to-face schooling ended. His admission that he missed someone was the first time he had ever expressed an emotion other than anger, and the very first time he did so unprompted by his teacher, or aide, or me.

\section{Summary}

Constantino et al. (2020) outlined important considerations for clinicians regarding the impact of the COVID-19 global pandemic on individuals with intellectual and developmental disabilities (e.g. ASD). The researchers emphasized the loss of direct care from a support provider should neither be taken lightly, nor should the impact of limited social contact for individuals with ASD, who often require physical proximity and interactions to make their lives as optimal and fulfilled as possible (Constantino et al. (2020). That is, in addition to potential academic hardships, those with limited social and communication abilities face unique challenges that can have longer-term (e.g. post-secondary) affects (Roitsch and Horn, 2020). Nonetheless, Constantino et al. (2020) suggest some students with ASD may be thriving at home, as they no longer have to contend with school pressures and overstimulation (e.g. noise volume, fluorescent lights) that brick-and-mortar schools often create.

Reicher and Stott (2020) found the transition to online learning during the COVID-19 global pandemic to be beneficial for students with ASD. Students with ASD who have excelled online reported reduced anxiety compared to face-to-face learning experiences. Additionally, Reicher and Stott (2020) highlighted the elimination of overstimulation caused by loud school bells, changing of classrooms and cafeteria smells observed during schoolbased learning was a benefit for students with ASD. The authors further suggest that 
information gathered during the COVID-19 global pandemic can help educators optimate academic achievement by creating learning environments based on individual student needs and abilities (Reicher \& Stott, 2020). However, less is known about the longer-term effects of virtual instruction for individuals with ASD. Though some preliminary research suggests positive learning outcomes have resulted over recent months for students with ASD, it is difficult to reliably measure the generalization and transfer of acquired skills. Sustainability data will also help determine the effects of learning acquisition during this unprecedented time.

In response to the COVID-19 pandemic, Stenhoff et al. (2020) provide strategies for caregivers and teachers to ensure instructional materials, as well as communication and behavioral supports are in place for students with ASD, specifically for those who live in rural settings. The development of instructional educational materials for home use is important, but, so too is the communication exchange about support materials (to ensure comprehension of topics being taught) especially for students with disabilities (Stenhoff et al., 2020). Stenhoff et al. (2020) further suggest that establishing ongoing lines of collaborative communication with parents or caregivers cannot be understated when addressing online teaching for students. Teachers have several distance education methods available to help caregivers as they facilitate virtual learning in the home. For example, teachers can provide materials, develop recorded lessons and activities and teach directly to students via learning management systems (platforms available online such as Google Classroom).

\section{Conclusion}

Since March of 2020, students, parents and educators around the globe have been adapting to virtual learning. Though this abrupt shift in instructional modality has been an adjustment for all, students with disabilities and their families faced unique challenges. By interviewing the parent of a child with ASD, we sought to understand some of the benefits and challenges as they relate to virtual learning for this unique population of students. We hope that the insights shared and themes that emerged from our work will help bring awareness to the impact of changes in routines and roles, instruction, social impact, benefits and challenges of technology and learning for students with ASD during the COVID-19 pandemic and beyond. Based on our findings, we encourage parents and special education teachers to work together collaboratively as they consider the individualized technology needs of the student to produce optimal learning outcomes that will be sustained over time.

\section{References}

Able, H., Sreckovic, M.A., Schultz, T.R., Garwood, J.D. and Sherman, J. (2015), "Views from the trenches: teacher and student supports needed for full inclusion of students with ASD," Teacher Education and Special Education: The Journal of the Teacher Education Division of the Council for Exceptional Children, Vol. 38 No. 1, pp. 44-57.

Adedoyin, O.B. and Soykan, E. (2020), "Covid-19 pandemic and online learning: the challenges and opportunities," Interactive Learning Environments, Taylor \& Francis, pp. 1-13.

American Psychiatric Association (2013), Diagnostic and Statistical Manual of Mental Disorders, 5th ed., American Psychiatric Association, available at: https://doi.org/10.1176/appi.books.978089042 5596

Applied Behavior Analysis Program Guide (2020), "5 ways autism can affect learning," available at: www.appliedbehavioranalysisprograms.com/lists/5-ways-autism-can-affect-learning/ (accessed 18 November 2020).

Ayres, K.M., Maguire, A. and McClimon, D. (2009), "Acquisition and generalization of chained tasks taught with computer based video instruction to children with autism," Education and Training in Developmental Disabilities, Vol. 44 No. 4, pp. 493-508. 
Brenan, M. (2020), "42\% of parents worry COVID-19 will affect child's education," Gallup, 31 March, available at: https://news.gallup.com/poll/305819/parents-worry-covid-affect-child-education.aspx? utm_source=twitter\&utm_medium=o_social_adef0736-7a4a-4cae-b18f-b0d161d985d7\&utm_term= gallupedu\&utm_content=\&utm_campaign=

Centers for Disease Control (2020), "Autism spectrum disorder (ASD)," available at: www.cdc.gov/ ncbddd/autism/index.html (accessed 18 November 2020).

Constantino, J.N., Sahin, M., Piven, J., Rodgers, R. and Tschida, J. (2020), "The impact of COVID-19 on individuals with intellectual and developmental disabilities: Clinical and scientific priorities," American Journal of Psychiatry, Vol. 177 No. 11, pp. 1091-1093.

Hodges, C., Moore, S., Lockee, B., Trust, T. and Bond, A. (2020), "The difference between emergency remote teaching and online learning," EDUCAUSE Review Online, available at: https://er.educause.edu/ articles/2020/3/the-difference-between-emergency-remote-teaching-and-online-learning (accessed 19 May 2020).

Horn, A.L., Layden, S.J. and Bobzien, J. (2021), "Where are you? Young adults with autism calling and texting location following video modeling instruction," Career Development and Transition for Exceptional Individuals, Vol. 44 No. 1, pp. 17-27.

Kandalaft, M.R., Didehbani, N., Krawczyk, D.C., Allen, T.T. and Chapman, S.B. (2013), "Virtual reality social cognition training for young adults with high-functioning autism," Journal of Autism and Developmental Disorders, Vol. 43 No. 1, pp. 34-44.

Kluth, P. and Schwarz, P. (2008), Just Give Him the Whale, Paul H. Brookes, London.

Maenner, M.J., Shaw, K.A., Baio, J., Washington, A., Patrick, M., DiRienzo, M., Christensen, D.L., et al. (2020), "Prevalence of autism spectrum disorder among children aged 8 years - autism and development disabilities monitoring network, 11 sites, United States, 2016," MMWR. Surveillance Summaries, Vol. 69 No. 4, pp. 1-12.

Masonbrink, A.R. and Hurley, E. (2020), "Advocating for children during the COVID-19 school closures," Pediatrics, Vol. 146 No. 3, pp. 1-4.

Mazurek, M.O., Shattuck, P.T., Wagner, M. and Cooper, B.P. (2012), "Prevalence and correlates of screen-based media use among youths with autism spectrum disorders," Journal of Autism and Developmental Disorders, Vol. 42 No. 8, pp. 1757-1767.

Moore, R.L. (2016), "Interacting at a distance: creating engagement in online learning environments," in KyeiBlankson, L., Blankson, J., Ntuli, E. and Agyeman, C. (Eds), Handbook of Research on Strategic Management of Interaction, Presence, and Participation in Online Courses, IGI Global, Hershey, PA, pp. 401-425.

Moore, R.L. (2020), "Developing lifelong learning with heutagogy: contexts, critiques, and challenges," Distance Education, Vol. 41 No. 3, pp. 381-401.

Must, A., Phillips, S., Curtin, C. and Bandini, L.G. (2015), "Barriers to physical activity in children with autism spectrum disorders: relationship to physical activity and screen time," Journal of Physical Activity and Health, Vol. 12 No. 4, pp. 529-534.

Noguchi, Y. (2020), "Coronavirus triple duty: working, parenting, and teaching from home," NPR, All Things Considered, 17 March, available at: www.npr.org/2020/03/17/816631571/coronavirus-triple-dutyworking-parenting-and-teaching-from-home

Oyarzun, B., Martin, F. and Moore, R.L. (2020), "Time management matters: online faculty perceptions of helpfulness of time management strategies," Distance Education, Vol. 41 No. 1, pp. 106-127.

Parsons, S. and Mitchell, P. (2002), "The potential of virtual reality in social skills training for people with autistic spectrum disorders," Journal of Intellectual Disability Research, Vol. 46 No. 5, pp. 430-443.

Pellicano, E. Brett, S., den Houting, J., Heyworth, M., Magiati, I., Steward, R., Urbanowicz, A. et al. (2020), "II want to see My friends': the everyday experiences of autistic people and their families during COVID19," Sydney, available at: www.sydney.edu.au/dam/corporate/documents/sydney-policy-lab/everydayexperiences-of-autistic-people-during-covid-19--report--july-2020.pdf

Reicher, S. and Stott, C. (2020), "On order and disorder during the COVID-19 pandemic," British Journal of Social Psychology, Vol. 59 No. 3, pp. 694-702.

Reynolds, M. (2020), "Teacher connects with students using social media during COVID-19 pandemic," KAIT 8 News, available at: www.kait8.com/2020/04/25/teacher-connects-with-students-using-socialmedia-during-covid-pandemic/ (accessed 19 May 2020). 
Roitsch, J. and Horn, A.L. (2020), "Standardized and informal language assessments determining the communications needs of transition-age students with mild intellectual disability," EBP Briefs, Vol. 14 No. 5, pp. 1-9.

Romano, M., Osborne, L.A., Truzoli, R. and Reed, P. (2013), "Differential psychological impact of internet exposure on internet addicts," PLOS ONE, Vol. 8 No. 2, edited by Hidalgo, C.A., available at: https://doi. org/10.1371/journal.pone.0055162

Schuck, R.K. and Lambert, R. (2020), “'Am I doing enough?' Special educators' experiences with emergency remote teaching in spring 2020," Education Sciences, Vol. 10 No. 11, p. 320.

Stenhoff, D.M., Pennington, R.C. and Tapp, M.C. (2020), "Distance education support for students with autism spectrum disorder and complex needs during COVID-19 and school closures," Rural Special Education Quarterly, Vol. 39 No. 4, pp. 211-219.

Tate, E. (2020), "'Let yourself off the hook': advice for teachers and parents during COVID-19," EdSurge Podcast, 24 March, available at: www.edsurge.com/news/2020-03-24-let-yourself-off-the-hook-advicefor-teachers-and-parents-during-covid-19

UNESCO (2020), "COVID-19 impact on education," available at: https://en.unesco.org/covid19/ educationresponse (accessed 23 November 2020).

Valencia, K., Rusu, C., Quiñones, D. and Jamet, E. (2019), "The impact of technology on people with autism spectrum disorder: a systematic literature review,” Sensors, Vol. 19 No. 20, p. 4485.

Yuan, S.N.V. and Ip, H.H.S. (2018), "Using virtual reality to train emotional and social skills in children with autism spectrum disorder," London Journal of Primary Care, Vol. 10 No. 4, pp. 110-112.

\section{About the authors}

Jane Roitsch is an Assistant Professor in the Department of Communication Disorders and Special Education at Old Dominion University. She teaches anatomy and physiology, phonetics and articulation disorders and her research interests include executive functions, cognition, anatomy, dysphagia, voice and fluency disorders. Jane Roitsch is the corresponding author and can be contacted at: jroitsch@odu.edu

Robert L. Moore is an Assistant Professor of Educational Technology in the School of Teaching and Learning at the University of Florida. His research analyzes online learning environments, focusing on massive open online courses (MOOCs), to identify ways to improve student learning in those contexts. He is particularly interested in leveraging learning analytics to ensure that online learning environments offer similar critical thinking and engagement levels as in face-to-face instruction.

Annemarie L. Horn is an Assistant Professor in the Department of Communication Disorders and Special Education at Old Dominion University. She is currently serving as the Program Coordinator for the MSED Adapted Curriculum Program. Research interests include teacher preparation, as it relates to improving post-secondary outcomes for youth with disabilities.

For instructions on how to order reprints of this article, please visit our website: www.emeraldgrouppublishing.com/licensing/reprints.htm

Or contact us for further details: permissions@emeraldinsight.com 